\title{
АНАЛИЗ НЕЙРОФИЗИОЛОГИЧЕСКИХ И НЕЙРОХИМИЧЕСКИХ МЕХАНИЗМОВ СУБСИНДРОМОВ ПОВЕДЕНЧЕСКОГО ДЕПРЕССИВНОГО СИНДРОМА
}

Термин «депрессивный синдром» несет различную смысловую нагрузку. Чаще всего под этим подразумевают психопатологический синдром, включающий психологические, эмоциональные и вегетативные проявления. Наиболее часто депрессивный синдром имеет место при монополярной (большой) и биполярной депрессии, при шизофрении, при нейродегенеративных заболеваниях (болезни Альцгеймера, паркинсонизме, рассеянном склерозе и др.), при соматических заболеваниях (метаболический синдром, сахарный диабет, гипер- и гипотирео3, гипогонадизм, сердечно-сосудистые, воспалительные заболевания и др.), как результат побочного действия лекарств, особенно иммунотропных; наконец, при развитии зависимости к фармакологическим средствам $[1,2]$.

Столь широкое распространение депрессивного синдрома указывает на его гетерогенность, нейрофизиологическую и нейрохимическую многоликость. Анализ депрессии как отдельной нозологической единицы неотвратимо ведет к появлению новых диагнозов в связи с увеличением количества субсиндромов. Более того, отдельная область нейронаук - биологическая психиатрия фиксирует внимание на коррелятах специфических компонентов отдельных субсиндромов депрессии. Это лишний раз подчеркивает, что депрессия - комплексное расстройство и многомерный феномен. Считают, что нет естественной и четкой границы между дистимией, большим, малым и остаточным субсиндромами депрессивного уровня. Все это части психопатологического континуума с общими депрессивными чертами. Однако отдельные части этого континуума могут быть синдромами не депрессивной природы [3]. Это подтверждается и тем, что антидепрессанты проявляют свою терапевтическую активность не только при депрессии, но и при дистимии, тревожнофобических расстройствах, при панических, обсессивно-компульсивных и посттравматических стресс-индуцируемых расстройствах. Важно при этом отметить, что антидепрессанты при воздействии на психические процессы здоровых добровольцев не вызывают их существенных изменений.

Наиболее полное представление о природе того или иного субсиндрома, являющегося составной частью депрессивного синдрома, можно получить на уровне доказательств в том случае, если этот субсиндром можно смоделировать на животных. В противном случае представления о природе субсиндрома будут носить характер предположения. Такие субсиндромы депрессивного синдрома, как патологически сниженное настроение, чувство безысходности, идеи самообвинения и самоуничижения, суицидальные идеи невозможно смоделировать на животных. В то же время, ряд субсиндромов, а именно существенное ослабление мотиваций, проявляющееся беспомощностью, «поведение отчаяния»; снижение интереса к событиям, которые приносят удовольствие - ангедония; нарушения сна и аппетита, ограничение социальных контактов, возросший уровень тревожности и др. более или менее успешно моделируются не только на приматах, но и на грызунах $[4,5]$.

\section{Субсиндром снижения мотиваций}

Лимбическая система в мозге человека выполняет множество функций, одна из которых мотивационно-эмоциональная. Каждый организм, включая организм человека, имеет целый набор биологических потребностей. К ним, например, относятся потребность в пище, воде, тепле, размножении и многое другое. Для достижения какой-то определенной биологической потребности в организме складывается функциональная система. Ведущим системообразующим фактором является достижение определенного результата, соответствующего потребностям организма в данный момент. Мотивации - это различные побуждения или внутрен-

(с) И.И. Абрамец, Ю.В. Кузнецов, Д.В. Евдокимов, T.О. Зайка, 2019

(c) Университетская Клиника, 2019 
ние состояния, которые направляют поведение или выбор в рамках от коррекции гомеостатического дисбаланса до психосоциальных потребностей. Ключевой мотиватор нашей жизни - вознаграждение (удовольствие). В первом приближении мотивационные состояния делят на два типа: элементарные состояния (голод, жажда, холод); и персональные или социальные потребности [6].

Нейроанатомическая система формирования мотиваций включает ряд кортикальных и подкорковых структур лимбической системы мозга, включающие переднюю поясную кору (ППК), медиальную префронтальную кору (мПФК), прилежащее ядро (ПЯ), миндалину, вентральную тегментальную область (ВТО). Контролирующие модули префронтальной коры управляют активностью базальных ганглиев, которые тесно связаны с центральной структурой мотиваций гипоталамусом. Мотивации возникают при взаимодействии эмоций и сознания.

Центральная структура формирования мотиваций - ПЯ, которое делят на две части: сердцевину - центральную часть и раковину, занимающую вентральную и медиальную части ядра. Раковина участвует в реакциях вознаграждения и определяет мотивационное поведение, в т. ч. стремление к употреблению веществ. Интересно, что снижение активности нейронов ростральных отделов медиальной раковины вызывает интенсивное поедание пищи, даже сытыми животными; подобное воздействие на каудальные отделы раковины вызывает отвращение, страх и имитацию поведения защиты от нападения хищника [7].

В клинических и экспериментальных исследованиях на грызунах установлено, что ПЯ играет ключевую роль в депрессивной симптоматологии, включая ослабление мотиваций. Установлено, что стрессогенные стимулы нарушают функциональную активность афферентных входов в ПЯ вследствие изменений клеточных и молекулярных механизмов и это приводит к развитию депрессивно-подобного поведения. У больных с резистентной депрессией высокочастотная глубокая стимуляция мозга (в том числе и ПЯ) оказывает антидепрессивное действие [8].

В развитии депрессивного фенотипа поведения остается невыясненной роль двух подтипов среднешипиковых нейронов ПЯ, экспрессирующих Д1 и Д2 дофаминовые (ДА) рецепторы, которые посылают разные проекции к базальным ганглиям и структурам вознаграждения. Д1-нейроны ПЯ проецируются к вентральному паллидуму, внутреннему бледному шару, ВТО и черной субстанции, в то время как экспрессирующие Д2 ДА рецепторы нейроны ПЯ проеци- руют только к вентральному паллидуму [9]. Эти две популяции нейронов функционируют совместно, обеспечивая нормальное поведение, в то время как нарушение равновесия влияний этих нейронов нарушает мотивационный статус. Активация нейронов с Д1 рецепторами облегчает позитивное вознаграждение, а активация рецепторов с Д2 рецепторами способствует развитию аверсии; ингибиция этих путей вызывает противоположные эффекты [10]. Установлено, что ослабление возбуждающих синаптических влияний на Д1, но не Д2 нейроны ПЯ вызывает снижение мотиваций у мышей, подвергнутых влиянию иммобилизационного стресса.

Остается неясным, какие возбуждающие афферентные входы вызывают двунаправленные изменения активности нейронов ПЯ. Установлено, что оптогенетические стимуляции мПФК или терминалей от мПФК к ПЯ повышают устойчивость грызунов к действию хронического защитного социального стресса (ХЗСС), а усиление активности Д2 нейронов ПЯ способствует развитию депрессивного фенотипа [11]. Однако исследования последних лет не подтверждают различную роль Д1 и Д2 нейронов ПЯ в развитии депрессивного фенотипа поведения. Так, установлено, что оптогенетическая активация обоих подтипов нейронов ПЯ способствовала возрастанию мотивации для получения пищевого позитивного подкрепления; с другой стороны, в этих же условиях сигнал начала выбора подкрепления активировал Д1 и Д2 нейроны ПЯ, а угнетение активности любой популяции нейронов немедленно после включения сигнала вызывало ослабление мотивации [12]. Нарушение мотиваций при моделировании поведенческой депрессии, вызываемой хроническим воспалением или снижением уровней моноаминов в мозге после введения резерпина, сопровождалось угнетением активности проекционных пирамидных нейронов V слоя мПФК и ослаблением возбуждающего драйва мПФК на среднешипиковые нейроны ПЯ.

ДАергические проекции от ВТО к ПЯ считают сердцевиной нейрональной сети вознаграждения, и мотивационные аспекты вознаграждения реализуются в рамках этой системы [13]. В исследованиях на мышах, у которых в ДАергических нейронах ВТО отсутствовали НМДА глутаматные рецепторы, а количество AMPА глутаматных рецепторов уменьшено до 10\%, установлено, что их двигательная координация и вознаграждаемое обучение практически не изменялись, но выявлен дефицит при выполнении поведенческих задач, требующих попыток их реализации. Это указывает на то, что глутаматергическая нейропередача в ДАергических нейро- 
нах ВТО является определяющим фактором мотивации, готовности осуществить больше попыток, чтобы достигнуть вознаграждения. ДАергические нейроны ВТО разряжаются либо тонически с частотй 1-5 Гц, либо высокочастотными вспышками. Считают, что фазическая вспышка является обучающим сигналом, который формирует ассоциацию между нейтральным сигналом (контекст) и последующим вознаграждаемым обучением. Основной источник фазических разрядов ДАергических нейронов - глутаматергические афференты. У мышей с 90\% угнетением Глу передачи в ДА нейронах сохраняется вознаграждение и реализуется вознаграждаемое обучение. Возможно, что для компенсации глутаматергического дефицита в ДА нейронах ВТО происходит ослабление ГАМКергической передачи, либо усиление Ацх-, 5-НТ- или пептидергических модулирующих влияний [14].

Еще одна структура мозга играет важную роль в мотивации избавления от угрожающей ситуации - это латеральное ядро уздечки (ЛУ). Типичное проявление нарушения мотивации избавления - иммобилизация животных в тесте вынужденного плавания. ЛУ преимущественно глутаматергическое ядро, получающее афферентные входы от лимбических структур, вовлеченных в реализацию мотивационных состояний (ПФК, ПЯ, миндалины, латерального гипоталамуса и др.). Основные проекции ЛУ направлены к ростромедиальному тегментальному ядру, ГАМКергические нейроны которого угнетают активность 5-НТ- и ДАергических нейронов ядер шва и ВТО соответственно [15]. В исследованиях мозга больных депрессией и грызунов при моделировании поведенческой депрессии выявлено повышение активности ЛУ. Рост активности моноаминергических нейронов приводит к усилению мотивированного поведения и развитию позитивного аффективного состояния. С другой стороны, установлено, что угнетение активности ДАергической мезолимбической системы сопровождается обесцениванием вознаграждения, уменьшением количества попыток его достижения и развитию иммобилизации. В исследованиях на крысах установлено, что во время иммобилизации животных в тесте вынужденного плавания, которая отражает угнетение мотивации к избавлению от угрожающей ситуации, усиливается возбуждающее влияние ЛУ на ростромедиальное тегментальное ядро; дополнительное возбуждение ЛУ во время плавания увеличивает продолжительность иммобилизации по сравнению с контролем, а угнетение активности ЛУ сокращает общее время иммобилизации крыс в этом аверсивном тесте. Помимо этого, возбуждение дан- ной структуры вызывало уменьшение попыток и даже утрату интереса к получению аппетитного вознаграждения, хотя не оказывало влияния на гедоническую ценность вознаграждения. Наконец, стимуляция ЛУ не вызывала существенных изменений двигательной активности и координации движений [16].

Ослабление мотиваций, проявляющееся усталостью, анергией - уменьшением попыток избавления от угрожающей ситуации (плавательный тест Порсолта) или выбора более ценного пищевого вознаграждения, наблюдается при вызванном воспалением депрессивном фенотипе поведения $[17,18]$. Эти изменения связывают с действием биомаркеров воспаления - С-реактивного белка и интерлейкинов (ИЛ-1, ИЛ-6). Введение липополисахаридов кишечной палочки, усиливающих образование этих биомаркеров, вызывало ослабление высвобождения ДА и снижение активности нейронов стриатума, что, в свою очередь, сопровождалось ослаблением мотиваций и угнетением целенаправленного поведения. В клинических исследованиях больных депрессией установлено, что уровни С-реактивного белка и провоспалительных интерлейкинов негативно коррелировали с ослаблением функциональных связей между ПЯ и мПФК и дорсального стриатума с мПФК и двигательными зонами коры. Эти изменения определяют соответственно снижение мотиваций и двигательную ретардацию и усталость [17].

Введение крысам провоспалительных цитокинов ИЛ-1 и ИЛ-6 меняло оперантное поведение животных, уменьшая количество не всегда вознаграждаемых нажатий на рычаги, но увеличивало количество поглощаемой свободнодоступной пищи, т. е. ослабляло мотивации получения высокозатратного, но облегчало реализацию низкозатратного вознаграждения. Эти эффекты интерлейкинов ослаблялись блокатором A2 аденозиновых рецепторов MSX-3 и психостимулятором метилфенидатом. В используемых дозах ИЛ-1 и ИЛ-6 не оказывали влияния на гедоническую привлекательность пищи и аппетит, но существенно снижали внеклеточный уровень ДА в ПЯ $[19,18]$. Следовательно, биомаркеры воспаления нарушают обмен ДА в вентральном и дорсальном стриатуме и вызывают ослабление мотиваций и двигательную заторможенность.

Одной из мишеней действия интерлейкинов является фермент индол-2,3-диоксигеназа (ИДО), который превращает триптофан в кинуренин и нарушает образование 5-HТ. К настоящему времени твердо установлено, что дефицит 5-НТ и накопление метаболитов кинуренина в мозге приводят к развитию депрессивного син- 
дрома. Введение мышам линии C57BL/6J липополисахаридов кишечной палочки снижало исследовательскую локомоторную активность, повышало уровень тревожности и на 20\% уменьшало показатель предпочтения потребления раствора сахарозы (частично связанный с мотивацией вознаграждения). Однократное системное введение мышам L-кинуренина вызывало ангедонический и анксиогенный эффекты, но не влияло на двигательную активность. Введение грызунам ингибитора ИДО 1-метилтриптофана ослабляло ангедоническое и анксиогенное, но не локомоторное действие липополисахаридов [20]. Эти данные указывают на участии ИДО в развитии депрессивного и тревожного поведения. Тем не менее, получены данные, указывающие на отсутствие влияния продуктов фермента ИДО на мотивационные аспекты депрессивного поведения. У мышей после введения липополисахаридов или повреждения седалищного нерва развивался депрессивный фенотип поведения с выраженными мотивационными нарушениями. Влияние липополисахаридов на мотивационные аспекты поведения наблюдали как у исходной линии, так и у мышей с генетическим дефектом ИДО. Кроме того, у мышей с повреждением нерва вырабатывали реакцию предпочтения места, в котором осуществляли ослабление нейропатической боли, и эта реакция не зависела от ИДО [21]. Эти данные указывают на то, что мотивационный компонент вызванной воспалением поведенческой депрессии не зависит от нарушения обмена 5-НТ.

\section{Субсиндром ангедонии}

Традиционно ангедонию определяют как «потерю удовольствия» и это подчеркивает утрату достигаемого, приносящего удовлетворение аспекта вознаграждения. Однако это расплывчатое определение нуждается в уточнениях. Начальная стадия вознаграждения - формирование ассоциации между соответствующим стимулом и вознаграждением, которая ведет к потребности вознаграждения, его предвкушению, мотивации, попыткам получить вознаграждение, гедонической реакции и оценке соотношения затрат для получения вознаграждения и его мерой [22].

Вознаграждение можно разделить на два типа: пища, секс - первичное (врожденное) и фотографии, деньги, чтение - приобретенное (не врожденное) вознаграждение. Наличие этих двух типов может усложнять исследования ангедонии вследствие их перекрывания либо независимого существования. Так для пищевого, монетарного и эротического вознаграждений имеются общие нейронные сети, включающие вентромедиальную префронтальную кору (ПФК), вентральный стриатум, миндалины, переднюю островковую кору и медиодорсальный таламус. В тоже время, пищевое вознаграждение активирует переднюю островковую кору и миндалины, а монетарное вознаграждение - орбитофронтальную кору. Даже в пределах новой коры врожденное и приобретенное вознаграждение кодируются в разных зонах. Например, монетарное вознаграждение кодируется филогенетически более молодыми передними участками орбитофронтальной коры, а эротическое вознаграждение - ее более древними задними участками [23]. Однако эти представления разделяются не всеми.

Наиболее адекватными моделями исследования субсиндрома ангедонии при депрессивном фенотипе поведения животных являются модели, в которых депрессивный синдром развивается вследствие воздействия хронического стресса (чаще защитного социального) и длится на протяжении нескольких недель. Наиболее часто состояние ангедонии оценивают по изменению показателей тестов предпочтения потребления сладкого раствора, предпочтения места воздействия и внутричерепной самостимуляции. В клинических условиях ангедония определяется по различным опросникам, каждый из которых может отражать различные аспекты вознаграждения, такие как мотивации, оценки и выбор парадигмы достижения. В доклинических исследованиях на животных представляется возможность проверить нейрональные маркеры этих аспектов вознаграждения, которые могут сопоставляться с результатами магниторезонансных исследований у людей с ангедонией $[24,25]$.

Вентральный стриатум (ПЯ) и орбитофронтальная кора (ОФК) кодируют удовольствие. Действительно, мю-опиооидные и эндоканнабиноидные рецепторы в ПЯ и вентральном паллидуме опосредуют гедоническое восприятие вознаграждения и активация этих рецепторов усиливает эмоциональную реакцию на пищевое вознаграждение, как сахар, жир, и т. п. Активация ГАМКА рецепторов в ПЯ также регулирует аффективные реакции на сахар. В исследованиях на людях показано, что субъективная оценка удовольствия опосредована ОФК, хотя не ясно, воспринимает или кодирует удовольствие ОФК. У больных униполярной (большой) депрессией выявлено снижение функциональной активности как ПЯ, так и ОФК [26].

Отдельные области ПФК регулируют разные аспекты вознаграждения. У здоровых людей выраженность ситуативной ангедонии негативно коррелирует с активностью ППК и дорсолатеральной ПФК. Однако у больных депрес- 
сией получены противоречивые результаты. В исследованиях на животных установлено, что ОФК кодирует оценку данного вознаграждения и сравнивает ее с оценками других вознаграждений. Определение ценности вознаграждения базируется на его гедоническом потенциале, затратах и приобретениях, связанных с данным вознаграждением. ППК, получая информацию от ОФК, определяет затраты (попытки) необходимые для получения вознаграждения; ее дорсальные части кодируют результаты предыдущего вознаграждения и последующий выбор парадигмы поведения [27]. При нарушении активности передней поясной коры субъект отдает предпочтение вознаграждениям малозатратным с низкой гедонической емкостью.

Исследования нейробиологической основы ангедонии традиционно связывают с мезолимбической системой, включающей проекции от ДАергических нейронов ВТО к ПЯ и нейронов черной субстанции к дорсальному стриатуму. Тяжесть ангедонии, но не депрессии у человека обнаруживает негативную корреляцию с активностью вентрального стриатума на приносящие удовольствие стимулы, монетарное вознаграждение, позитивные слова. Тяжесть ангедонии при паркинсонизме негативно коррелирует с мотивационными реакциями на аппетитные пищевые образы. Следовательно, снижение активности и объема стриатума вносят вклад в развитие ангедонии при аффективных расстройствах [28].

Хотя ДА непосредственно не участвует в восприятии удовольствия, его активность связывают с прогнозированием, предчувствием и мотивацией для получения удовольствия. Установлено, что проецирующие к ПЯ нейроны ВТО физически возбуждаются непредвиденным вознаграждением, т. е. ДА трансформирует поощрительную оценку вознаграждения в предшествующий вознаграждению сигнал [29]. Наоборот, если предполагаемое вознаграждение не реализуется, разряды ДАергических нейронов становятся менее частыми, тоническими. Следовательно, ДА в стриатуме определяет прогнозирование и предчувствие вознаграждения.

Что касается мотивации, то установлено, что снижение активности ДА в ПЯ с помощью снижения уровня амина или его антагонистов приводит к уменьшению вероятности получения вознаграждения, требующего больших затрат, но облегчает реализацию менее ценного и малозатратного вознаграждения. С другой стороны, презентация голодному человеку образа недоступной привлекательной пищи повышает ДАергическую активность стриатума.

Имеются данные, что миндалины участвуют в оценке вознаграждения. Так, опиоиды в базолатеральном ядре миндалины (БЛМ) опосредуют поощрительные свойства вознаграждения. Введение антагониста мю рецепторов налоксона в БЛМ ослабляло усиление потребления сахарозы при пищевой депривации, и не влияло на ее пищевую привлекательность [30]. Помимо этого, оптогенетическое угнетение глутаматергических проекций от БЛМ к ПЯ ослабляла потребление сахара. Следовательно, помимо ДАергической активности в ПЯ опиоидная и глутаматергическая активность БЛМ необходимы для гедонической оценки вознаграждения.

Межструктурные связи формирующих вознаграждение образований мозга позволяют: воспринимать стимулы удовольствия; регистрировать ценность вознаграждения и связанные с его получением затраты; определить необходимые для получения стимула попытки; принять решение о реализации этого стимула; ускорить и усилить мотивацию получения этого стимула. Гедоническое восприятие вознаграждения опосредовано опиоидной, ГАМКергической и эндоканнабиноидной системами ПЯ, вентрального паллидума и ОФК, которые получают входы от сенсорных зон коры и рассчитывают меру вознаграждения. Затем ОФК транслирует информацию о мере вознаграждения в переднюю поясную кору, где определяются затраты, приобретения и фиксируется история о том, сколько попыток требуется для осуществления возможных различных действий. Передняя поясная кора посылает проекции к вентромедиальной и дорсолатеральной ПФК, которые вовлечены в принятие решения, базирующегося на мере вознаграждения, попытках и истории, касающейся будущих действий. Глутаматергические афференты от ПФК передают эту информацию в ПЯ, которое получает ДА- и глутаматергические входы от ВТО и миндалин соответственно, которые обеспечивают поощрительное значение информации и усиливают мотивацию планируемого в ПФК целенаправленного действия. Особое значение придается глутаматергическим связям между корой и ПЯ и разными зонами коры. Действительно, кетамин и другие антагонисты НМДА глутаматных рецепторов обнаруживают быстро развивающееся антидепрессивное действие, которое связывают с опосредуемым AMPA глутаматными рецепторами усилением глутаматергической нейропередачи [31]. С другой стороны, разрушение глутаматергических проекций от мПФК к ПЯ, либо введение блокаторов АМРА глутаматных рецепторов в раковину ПЯ вызывает развитие безынициативности в получении вознаграждения. Отмена никотина после его хронического вве- 
дения повышает порог внутричерепной самостимуляции вследствие снижения глутаматергической активности (ослабление пресинаптического высвобождения глутамата), и наоборот, порог самостимуляции понижается при возрастании глутаматергической активности [32]. Следовательно, блокада или ослабление ДАергической передачи от ВТО к ПЯ, опиоидной нейропередачи в БЛМ, активности передней поясной коры и глутаматергической передачи от мПФК к ПЯ существенно снижают возможности получения вознаграждения, особенно требующего больших затрат.

Множественные реципрокные связи различных областей ПФК либо связей коры с ПЯ, ВТО, БЛМ и гиппокампом играют важную роль в регуляции поведенческих реакций на вознаграждение. Действительно, ослабления нейрогенеза в зубчатой извилине снижает показатели предпочтения потребления раствора сахарозы и обращает ослабление флуоксетином стрессиндуцируемой ангедонии у приматов. Хроническое введение избирательных серотонинпозитивных антидепрессантов повышало предпочтение сахарозы у мышей и активность вентрального стриатума у людей. В тоже время, антагонист 5-НТ2С рецепторов агомелатин оказывал такое же действие на мышей и уменьшал ангедонию у больных депрессией [33, 34]. Но влияние 5-НТ на систему вознаграждения неодно- значно и может быть опосредовано ДАергической системой, поскольку агомелатин, блокируя пресинаптические 5-НТ2С рецепторы, может усиливать высвобождение ДА (см. рис.).

ПЯ, вентральный (в) паллидум и ОФК воспринимают удовольствие. Относительная вознаграждающая ценность приносящего удовольствие стимула определяется ОФК. Попытки, необходимые для получения этого стимула, анализирует передняя поясная кора (ППК). Вентромедиальная (вм) ПФК вовлечена в выбор конкретной парадигмы целенаправленного поведения, обеспечивающего получение приносящего удовольствие стимула. ВТО и миндалины (МИНД) определяют предчувствие и мотивацию поведенческой активности, приносящей вознаграждение. Глутаматергические проекции гиппокампа (Гипп) поддерживают рабочий тонус ПЯ и вмПФК, и ослабление активности данной структуры способствует развитию ангедонии. Латеральная уздечка (лУзд) посылает возбуждающие проекции к тормозным ГАМКергическим нейронам ростромедиального тегментального ядра (рмТг), которые угнетают активность ДАергических нейронов ВТО. Повышение активности латеральной уздечки сопровождается развитием ангедонии.

\section{Субсиндром повышенной тревоги}

Депрессивному синдрому присуща высокая степень (50 и более \%) коморбидности с тревож-
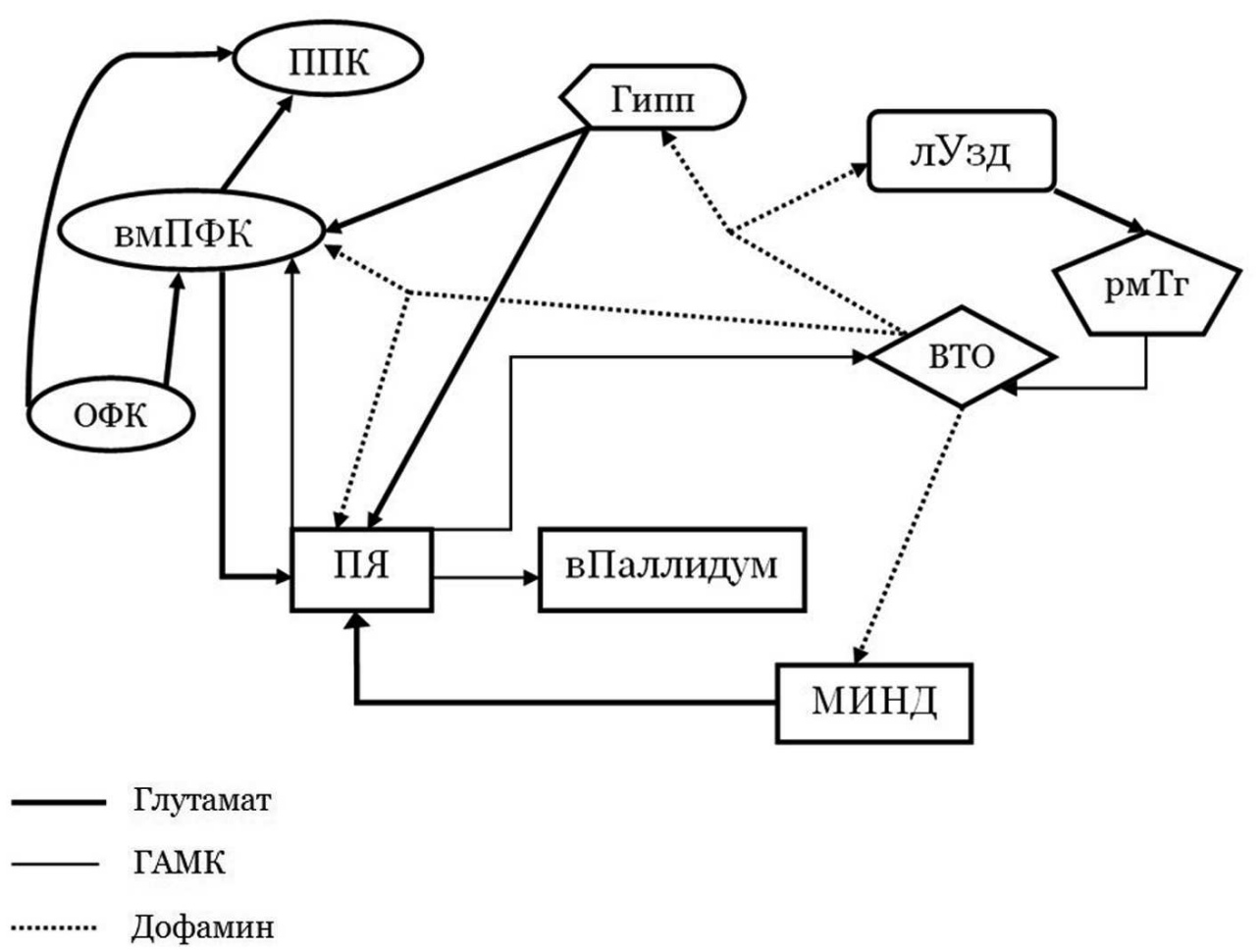

Рис. Упрощенная модель нервной сети ангедонии. 
ными расстройствами [35]. Общепризнано, что тревога является одним из основных признаков депрессии, а у пациентов с тревожной депрессией заболевание протекает тяжелее, с более выраженными суицидальными идеями и смертностью. С другой стороны, у больных тревожными расстройствами часто наблюдается депрессивная симптоматика. Некоторые симптомы генерализованного тревожного расстройства (ГТР) тревога, ангедония и бессонница - присущи также большой депрессии. Важно, что симптоматика большой депрессии и тревожных расстройств частично перекрывается. В основе этого лежит совпадение определенных лимбических структур, вовлеченных в развитие как депрессивных, так и тревожных расстройств.

Создание системы исследовательских доменных критериев (RDoC) [36] позволяет реконструировать психические расстройства на основе нейробиологических механизмов, объясняющих симптомы традиционных диагнозов. Одним из таких доменов в системе RDoC является негативная валентная система, включающая реакции на аверсивные ситуации - страх, тревогу, постоянную угрозу и утрату вознаграждения, которая соответствует используемому в клинической психологической литературе понятию склонность (подверженность) негативным аффектам. В развитие депрессивных и тревожных расстройств вовлечена негативная валентная система.

В психологической литературе тревога определяется как длительное состояние возбуждения в ожидании отдаленной либо непредсказуемой опасности. Напротив, страх является реакцией «борьбы или бегства» и всегда сопровождается защитной реакцией против сиюминутной угрозы, которая угасает после исчезновения угрозы. В исследованиях на животных установлено, что реакция страха связана с центральным ядром миндалин (ЦМ), а тревожные реакции ассоциируют с ядром ложа конечной полоски и обе реакции жестко связаны с БЛМ [37]. Деятельность ядер миндалин контролирует кора, в частности ПФК. Так ее отдел - инфралимбическая кора (ИЛ) способствует угашению страха, а прелимбическая кора (ПЛ), напротив, способствует экспрессии условного страха через посредство миндалин. У приматов активность дорсальной ППК коррелирует с активностью БЛМ при формировании условного страха, а у грызунов в этих же условиях возрастает активность ПЛ. Накапливаются данные о двухсторонних влияниях связей между БЛМ и отделами ПФК. Действительно, активность нейронов БЛМ, проецирующих к ПЛ, возрастает при формировании условного страха, при погашении этой реакции также растет активность дающих проекции к ИЛ нейронов БЛМ [38]. Аналогичные результаты получены и у приматов.

Включение негативной валентной системы у больных тревожными и депрессивными расстройствами может быть обусловлено нарушением функций ПФК. У больных с тревожными расстройствами выявлено снижение активности вентромедиальной ПФК (гомолог ИЛ грызунов), но повышена активность гомолога ПЛ грызунов - дорсальной ППК. Дорсальные отделы ПФК подразделяют на передние и задние, причем ростральные отделы дорсальной ПФК и ППК вовлечены в осознание и оценку угрозы. Повышение активности ростральных отделов особенно дорсальной ППК выявлено у больных депрессивными и тревожными расстройствами [39]. С другой стороны, вентральные отделы ПФК вовлечены в ослабление активности негативной валентной системы. Действительно, в исследованиях на приматах показано, что повреждение передних отделов ОФК и вентролатеральной ПФК сопровождалось увеличением уровня тревожности [40]. Таким образом, вызванные различными причинами нарушения активности отдельных структур и межструктурных связей миндалин и ПФК определяет развитие тревожных и депрессивных расстройств у подверженных этому субъектов.

На взаимное перекрытие структур и механизмов, вовлеченных в развитие тревожных и депрессивных расстройств, указывает и то обстоятельство, что лекарства с определенным нейрохимическим механизмом действия ослабляют проявления и тревоги, и депрессии. В первую очередь это касается серотонинопозитивных средств. Установлено, что 5-НТ способствует поддержанию баланса между обработкой вознаграждающей и аверсивной информации и особенно в ингибиции образований ПФК, формирующих негативную валентную систему. Уменьшение уровня 5-НТ в мозге при снижении доступности триптофана способствует развитию тревоги, а повышение уровня 5-НТ снижает активность дорсальных префронтальных структур и уменьшает склонность к негативным эмоциональным состояниям [41]. В исследованиях на приматах установлено, что 5-НТ усиливает активность вентральных отделов ПФК, которые угнетают обработку аверсивной информации, а угнетение амином дорсальных отделов ПФК нарушает реализацию негативного аффекта. Следовательно, повышающие уровень серотонина в ПФК селективные ингибиторы обратного захвата серотонина уравновешивают активности и влияние на миндалины дорсальных и вентральных отделов ПФК и ослабляют нега- 
тивный эмоциональный фон, как при депрессии, так и при тревожных расстройствах. С другой стороны, бензодиазепиновые транквилизаторы, усиливая процессы ГАМКергического торможения, вызывают тотальное снижение активности миндалин и ростральных и вентральных отделов ПФК. В этой связи данная группа психофармакологических средств демонстрирует выраженное противотревожное действие и отсутствие или минимальное антидепрессивное действие [42].

\section{Субсиндром нарушения сна}

Наиболее типичными нарушениями сна при большой депрессии являются бессонница и гиперсомния, которые наблюдаются у 88\% и 27\% больных депрессией соответственно [43]. Взаимоотношения между бессонницей и депрессией двухсторонние: ухудшение качества сна предшествует обострению заболевания, а сниженное настроение нарушает нормальный сон. Более того, депрессия в 3 раза чаще развивается у людей с бессонницей по сравнению с субъектами с ненарушенным сном. Гиперсомния, усталость и сонливость часто позитивно коррелируют с депрессивной симптоматикой. Наконец, больные с депрессивными расстройствами неадекватно оценивают качество сна, латентность возникновения сна и его продолжительность [44].

Полисомнографические исследования выявляют нарушение архитектуры сна при депрессии. У больных выявлено увеличение времени засыпания, частые ночные пробуждения и фрагментацию сна; кроме того, наблюдали снижение латентности наступления сна с быстрыми движениями глаз (REM), удлинение периодов и общей продолжительности REM сна и увеличением частоты движений глаз в это время [45]. Относительный избыток REM сна приводит к укорочению продолжительности стадии N3 сна, т. е. медленноволнового сна, и его архитектуры.

Нейрофизиологические и нейрохимические механизмы нарушений сна при депрессии интенсивно изучались в исследованиях на животных. Так у крыс, подвергнутых воздействию трехнедельного умеренного непредсказуемого стресса, наблюдали уменьшение активного бодрствования и глубины сна, уменьшение латентности включения и продолжительности каждого эпизода REM сна. Аналогичные нарушения структуры сна на фоне поведенческой депрессии описаны у потомства самок крыс, которые в последние 10 дней беременности подвергались воздействию иммобилизационного стресса. Поскольку стрессогенные воздействия сопровождаются повышением уровня кортикостерона у грызунов, нарушения структуры сна может быть обусловлено действием глюкокор- тикоидов. Однако при поведенческой депрессии, вызванной хроническим на протяжении 2 недель введением кортикостерона, наблюдали повышение сонливости, обусловленное увеличением количества эпизодов медленноволнового сна без изменения их средней продолжительности. Параллельно с этим уменьшалась продолжительность бодрствования, несмотря на увеличение количества его эпизодов. REM сон в этих условиях практически не изменялся. Следовательно, наиболее типичные нарушения сна при большой депрессии лишь отчасти связаны с повышением уровня глюкокортикоидов и это касается, главным образом, укорочения продолжительности периода бодрствования. Помимо глюкокортикоидов, продолжительность сна регулируется высвобождающим кортикотропин гормоном. Действительно, введение больным депрессией антагониста этого гормона R121919 увеличивало продолжительность медленноволнового сна. Генетические дефекты, а именно полиморфизм гена МАО А и промоутера гена, кодирующего транспортер серотонина, и угнетение его активности антидепрессантом циталопрамом в первые дни применения препарата сопровождаются выраженной бессонницей у больных депрессией. Последние факты указывают на то, что нарушение обмена 5-НТ и норадреналина сопровождается расстройствами сна [46, 47].

Действительно установлено, что моноаминергические механизмы вовлечены в регуляцию и сна, и настроения. Так, переходу от медленноволнового к REM сну предшествует быстрое снижение активности 5-НТ-, ДА- и норадренергических нейронов и связанное с этим повышение активности холинергических нейронов [48]. В условиях депрессии активность моноаминергических и холинергических нейронов мозга нарушена. Об этом свидетельствует то, что клинически активные антидепрессанты повышают уровни моноаминов в мозге, а блокаторы М-холинорецепторов, ослабляющие влияния холинергических нейронов, обладают антидепрессивной активностью. Все группы моноаминергических нейронов входят в систему, поддерживающую бодрствующее состояния, поскольку имеют обширные проекции к различным участкам коры, на нейроны которой оказывают возбуждающее действие. С другой стороны, «генератор сна» - вентролатеральная преоптическая область содержит длинноаксонные ГАМКергические нейроны, которые угнетают активность поддерживающих бодрствующее состояние мозга моноаминергических нейронов $[48,49]$.

Помимо ядер гипоталамуса модулирующее 
влияние на моноаминергические нейроны оказывают некоторые заднемозговые ядра. Это относится к латеральной уздечке, при стимуляции которой угнетается активность 5-НТ- и ДАергических нейронов. Ослабление депрессивной симптоматики и нарушений сна при хроническом назначении антидепрессантов группы СИО3С связывают с угнетающим действием 5-НТ на возбуждающие пресинаптические терминали и ослаблением гиперактивации латеральной уздечки. ДА же оказывает возбуждающее действие на данную структуру. Установлено, что повреждение латеральной уздечки уменьшает продолжительность REM сна. Считают, что данная структура необходима для поддержки REM сна и ее влияние на архитектуру сна опосредовано 5-НТ-ергической активностью. Действительно, экспериментальные и клинические наблюдения показывают, что гиперактивность латеральной уздечки сопровождается снижением мотиваций, двигательной и речевой ретардацией и увеличением продолжительности REM сна, которые наблюдаются при депрессии [50].

Глутаматергическая система мозга играет важную роль в развитии сна, особенно появлению медленных таламокортикальных осцилляций в периоды медленноволнового сна. Ослабление опосредуемой AMPА глутаматными рецепторами межнейронной передачи в коре выявлено при моделировании депрессии у животных. Глутамат при активации АМРА и содержащих GluN2A субъединицы НМДА глутаматных рецепторов оказывает выраженное церебропротективное действие. Гипоактивность глутаматергической системы приводит к повреждению и гибели нейронов тех структур мозга, которые регулируют настроение и сон. Некоторые антидепрессанты (флуоксетин) и обладающие антидепрессивной активность блокаторы НМДА глутаматных рецепторов, в частности кетамин, и АМРАкины повышают активность глутаматергической системы мозга и ослабляют депрессивную симптоматику, в том числе и нарушения сна [51].

\section{Субсиндром нарушения аппетита}

Помимо основных проявлений депрессивного синдрома - сниженного настроения и потери интереса к жизни и удовольствиям - наблюдаются и вегетативные проявления, в частности усиление или утрата аппетита. Действительно, у 48\% больных большой депрессией выявлено снижение аппетита, а у 35\% больных наблюдали повышение аппетита. Характер изменения веса или аппетита наряду с другими симптомами может указывать на конкретную форму депрессивного расстройства. Так снижение веса и утрата аппетита в большей степени присущи большой депрессии; в то время как нервная булимия более характерна для атипичной депрессии [52].

Вариабельность симптомов лишний раз подчеркивает то обстоятельство, что депрессия не унитарное заболевание. С позиций нейробиологии симптомы депрессивного расстройства обусловлены различными и зачастую реципрокными нарушениями связей между структурами мозга, формирующими сознание, восприятие и вознаграждение, которые, в свою очередь, вовлечены в регуляцию эмоций. Правильное понимание индивидуальных различий в нарушениях функций региональных «узлов» нейросетей, формирующих эмоции, позволяет осуществлять более эффективное лечение отдельных форм депрессивных расстройств [36].

Регуляцию аппетита, потребление пищи и массу тела первично осуществляет гипоталамус. В последнем выделяют «центр потребления пищи» (голода) - латеральный гипоталамус и «центр насыщения» - вентромедиальные ядра гипоталамуса, особенно аркуатное ядро. Активность нейронов указанных ядер гипоталамуса изменяется в результате действия ряда гуморальных (инсулин, глюкагоно-подобные пептиды, лептин, грелин и др.) и нервных (афферентные волокна вагуса) факторов. С другой стороны, активность гипоталамических ядер и пищевое поведение существенно модулируются нисходящими влияниями ПЯ, а последняя структура осуществляет интеграцию мотиваций и последующего поведения [53]. Установлено, что блокада AMPA глутаматных, активация ГАМКА или мю-опиатных рецепторов в раковине ПЯ существенно повышают аппетит и потребление пищи независимо от исходного состояния. При этом агонист ГАМКА рецепторов мусцимол усиливал потребление пищи богатой углеводами и жирами, а опиоиды стимулировали потребление только жирной пищи [54]. Далее показано, что фармакологическое угнетение активности латерального гипоталамуса препятствует повышению аппетита и потребления пищи после блокады АМРА глутаматных рецепторов в раковине ПЯ [55]. В свою очередь, контролирующие аппетит и пищевое поведение структуры ПЯ получают модулирующие входы со стороны лимбической системы мозга. Действительно, ПФК, ОФК и островковая кора осуществляют исполнительный контроль; гиппокамп связывает поведение с существующим контекстом; БЛМ осуществляет эмоциональную маркировку поступающих сигналов, а ДАергические нейроны ВТО повышают чувствительность нейронов ПЯ к приходящим афферентным сигналам [53].

Различные аспекты изменений аппетита на 
пищевые раздражители связаны с активностью сложной системы, включающей ОФК, вентромедиальную ПФК, островковую кору, миндалины и стрио-паллидарную систему [56, 57]. Повышение и снижение аппетита являются симптомамиантиподами в диагностике большой депрессии и нервные субстраты этих изменений еще не выяснены. Наблюдаемые при депрессии изменения аппетита могут быть обусловлены множеством нарушений в различных нейросетях. Функциональные магниторезонансные исследования позволяют выяснить эти нарушения.

В этих исследованиях установлено, что предъявление пищевых стимулов больным депрессией с повышенным аппетитом вызывало увеличение активности в ОФК и островковой коре, а также в вентральном стриатуме, ограде, и вентральном паллидуме. У больных с анорексией выявлено снижение активности в передней и средней частях островковой коры и эти изменения выражены в большей степени по сравнению с больными с повышенным аппетитом и здоровыми субъектами [52]. Все структуры, в которых выявлены изменения активности, непосредственно или опосредовано принимают участие в регуляции настроения и пищевого поведения. Так, ОФК вовлечена в развитие большой депрессии, о чем свидетельствуют выявленные у больных снижение объема структуры и кровотока в ней [58]. Нарушения реакций вознаграждения и ангедонию при депрессии связывают с ослаблением активности и сниже- нием уровня ДА в вентральном стриатуме [59], который формирует пищевую мотивацию и гедоническое восприятие. Это распространяется на связанный с вентральным стриатумом вентральный паллидум. В свою очередь, инсулярную кору считают центром, интегрирующим активность интероцептивных центров и центров вознаграждения [60].

\section{З А К ЛЮ Ч Е Н ИЕ}

Депрессивный синдром, наблюдаемый при психических, неврологических и соматических заболеваниях, не является унитарным заболеванием. Это зачастую произвольный набор ряда субсиндромов, причем появление каждого из них непредсказуемо.

Ключевые субсиндромы депрессивного синдрома - патологически сниженное настроение, суицидальные идеи, ангедония, мыслительная и двигательная ретардация - обусловлены морфофункциональными нарушениями лимбических структур. Это касается ПФК, ПЯ, миндалин, гиппокампа.

Эти же структуры мозга вовлечены в реализацию поведенческих реакций, а именно мотиваций, реакций вознаграждения, сна и бодрствования, субъективной оценки окружения, потребления пищи. В связи со снижением функциональной активности ведущих лимбических структур первичная депрессивная симптоматика дополняется нарушениями мотиваций, вознаграждения, тревожности, сна и аппетита.

\section{И.И. Абрамец, Ю.В. Кузнецов, Д.В. Евдокимов, Т.О. Зайка}

ГОО ВПО «Донецкий национальный медицинский университет имени М. Горького», Донецк

\section{АНАЛИЗ НЕЙРОФИЗИОЛОГИЧЕСКИХ И НЕЙРОХИМИЧЕСКИХ МЕХАНИЗМОВ СУБСИНДРОМОВ ПОВЕДЕНЧЕСКОГО ДЕПРЕССИВНОГО СИНДРОМА}

Депрессивный синдром наблюдается при ряде психических, неврологических и соматических заболеваний. Столь широкое распространение синдрома указывает на гетерогенность составляющих его субсиндромов. Нейрофизиологическая и нейрохимическая гетерогенность заболевания затрудняет его лечение. В этом обзоре рассмотрены патофизиологические механизмы развития тех субсиндромов депрессивного расстройства, которые можно моделировать на животных. Это касается снижения мотиваций, определяющих парадигму поведения, ангедонии, повышения уровня тревожности, нарушений сна и аппетита. Приведены данные литературы, что в основе этих субсиндромов лежит ослабление возбуждающей нейропередачи и функциональных связей в лимбических структурах мозга - префронтальной коре, прилежащем ядре, миндалинах, гиппокампе и др.

Ключевые слова: депрессия, гипомотивации, ангедония, тревожность, нарушения сна, нарушения аппетита. 


\section{I.I. Abramets, Yu.V. Kuznetsov, D.V. Evdokimov, T.O. Zayka}

\section{SEI HPE «M. Gorky Donetsk National Medical University», Donetsk}

\section{ANALYSIS OF THE NEUROPHYSIOLOGICAL AND NEUROCHEMICAL MECHANISMS OF SUBSYNDROMES OF BEHAVIORAL DEPRESSIVE SYNDROME}

Depressive syndrome occurs in a number of mental, neurological and somatic illnesses. Such a wide syndrome dissemination indicates the heterogeneity of its constituent subsyndromes. Neurophysiological and neurochemical heterogeneity of illness complicates its treatment. This review covered the pathophysiological mechanisms of development of depressive disorder subsyndromes, which can be modeled in animals. This applies to decreasing the motivations that determine certain behav- ioral paradigms, anhedonia, increasing anxiety, sleep disturbances and appetite disorders. Literature data give evidences that the basis of these subsyndromes is the weakening of the excitatory neurotransmission and functional connections in the brain limbic structures - prefrontal cortex, nucleus accumbens, amygdala, hippocampus, etc.

Key words: depression, hypomotivation, anhedonia, anxiety, sleep disturbances, appetite disorders.

\section{ЛИТЕРАТУРА}

1. Kessler RC, Chiu WT, Demler O, et al. Prevalence, severity, and comorbidity of 12-month DSM-IV disorders in the National Comorbidity Survey Replication. Arch Gen Psychiatry. 2005; 62 (6): 617-27. doi:10.1001/archpsyc.62.6.617

2. Millan MJ. (2006). Multi-target strategies for the improved treatment of depressive states: Conceptual foundations and neuronal substrates, drug discovery and therapeutic application. Pharmacol Ther. 2006; 110 (2): 135-370. doi:10.1016/j.pharmthera.2005.11.006

3. Harro I, Oreland L. Depression as a spreading adjustment disorder of monoaminergic neurons: a case for primary implications of the locus coeruleus. Brain Res Rev. 2001; 38 (1): 79 - 128. PMID 11750928

4. Stepanichev M, Dygalo N.N, Grigoryan G, et al.. Rodent models of depression: neurotrophic and neuroinflammatory biomarkers. BioMed Research International. 2014, Article ID 932757, 20 pages,

http://dx.doi:10.1155/2014/932757

5. Abelaira HM, Reus GZ, Quevedo J. Animal models as tools to study the pathophysiology of depression. Revista Brasileira de Psiquiatria. 2013;35 (2): S112-S120. doi:10.1590/1516-4446-2013-1098

6. Вартанов А.В., Вартанова И.И. Эмоции, мотивация, потребность в филогенезе психики и мозга. Вестн. Москов. Ун-та, сер.14. Психология, 2005; (3): 20-35.

7. Reynolds SM, Berridge KC. Emotional environments retune the valence of appetitive versus fearful functions in nucleus accumbens. Nat Neurosci. 2008; 11 (4): 423-425. doi: $10.1038 / \mathrm{nn} 2061$

8. Russo SJ, Nestler EJ. The brain reward circuitry in mood disorders. Nat Rev Neurosci. 2013; 14 (9): 609-625. doi: 10.1038/nrn3381

9. Nicola SM. The nucleus accumbens as part of a basal ganglia action selection circuit. Psychopharmacology (Berl). 2007; 191 (3): 521-550. doi:10.1007/s00213-006-0510-4

10. Carlezon WA Jr, Thomas MJ. Biological substrates of reward and aversion: A nucleus accumbens activity hypothesis. Neuropharmacology. 2009; 56 (suppl 1): 122-132. doi: 10.1016/i.neuropharm.2008.06.075

11. Lobo MK, Zaman S, Damez-Werno DM et al. DeltaFosB induction in striatal medium spiny neuron subtypes in response to chronic pharmacological, emotional, and optogenetic stimuli. J Neurosci. 201333 (49): 18381-18395. doi: 10.1523/INEUROSCI.1875-13.2013

12. Natsubori A, Tsutsui-Kimura I, Nishida $\mathrm{H}$ et al. Ventrolateral striatal medium spiny neurons positively regulate food-incentive, goal-directed behavior independently of D1 and D2 selectivity. J Neurosci. 2017; 37 (10): 27232733. doi: 10.1523/JNEUROSCI.3377-16.2017

13. Bailey MR, Simpson EH, Balsam PD. Neural substrates underlying effort, time, and risk-based decision making in motivated behavior. Neurobiol Learn Mem. 2016; 133 (Sep): 233-256. doi: 10.1016/j.nlm.2016.07.015

\section{REFERENCES}

1. Kessler RC, Chiu WT, Demler O, et al. Prevalence, severity, and comorbidity of 12-month DSM-IV disorders in the National Comorbidity Survey Replication. Arch Gen Psychiatry. 2005; 62 (6): 617-27. doi:10.1001/archpsyc.62.6.617

2. Millan MJ. (2006). Multi-target strategies for the improved treatment of depressive states: Conceptual foundations and neuronal substrates, drug discovery and therapeutic application. Pharmacol Ther. 2006; 110 (2): 135-370. doi:10.1016/j.pharmthera.2005.11.006

3. Harro I, Oreland L. Depression as a spreading adjustment disorder of monoaminergic neurons: a case for primary implications of the locus coeruleus. Brain Res Rev. 2001; 38 (1): 79 - 128. PMID 11750928

4. Stepanichev M, Dygalo N.N, Grigoryan G. et al.. Rodent models of depression: neurotrophic and neuroinflammatory biomarkers. BioMed Research International. 2014, Article ID 932757, 20 pages,

http://dx.doi:10.1155/2014/932757

5. Abelaira HM, Reus GZ, Quevedo I. Animal models as tools to study the pathophysiology of depression. Revista Brasileira de Psiquiatria. 2013;35 (2): S112-S120. doi:10.1590/1516-4446-2013-1098

6. Vartanov A.V., Vartanova I.I. Emotsii, motivatsiya, potrebnost' v filogeneze psikhiki i mozga. Vestn. Moskov. Un-ta, ser.14. Psikhologiya, 2005; (3): 20-35 (in Russian).

7. Reynolds SM, Berridge KC. Emotional environments retune the valence of appetitive versus fearful functions in nucleus accumbens. Nat Neurosci. 2008; 11 (4): 423-425. doi: $10.1038 / \mathrm{nn} 2061$

8. Russo SJ, Nestler EJ. The brain reward circuitry in mood disorders. Nat Rev Neurosci. 2013; 14 (9): 609-625. doi: $10.1038 / \mathrm{nrn} 3381$

9. Nicola SM. The nucleus accumbens as part of a basal ganglia action selection circuit. Psychopharmacology (Berl). 2007; 191 (3): 521-550. doi:10.1007/s00213-006-0510-4

10. Carlezon WA Jr, Thomas MJ. Biological substrates of reward and aversion: A nucleus accumbens activity hypothesis. Neuropharmacology. 2009; 56 (suppl 1): 122-132. doi: 10.1016/j.neuropharm.2008.06.075

11. Lobo MK, Zaman S, Damez-Werno DM et al. DeltaFosB induction in striatal medium spiny neuron subtypes in response to chronic pharmacological, emotional, and optogenetic stimuli. J Neurosci. 201333 (49): 18381-18395. doi: 10.1523/JNEUROSCI.1875-13.2013

12. Natsubori A, Tsutsui-Kimura I, Nishida $\mathrm{H}$ et al. Ventrolateral striatal medium spiny neurons positively regulate food-incentive, goal-directed behavior independently of D1 and D2 selectivity. J Neurosci. 2017; 37 (10): 27232733. doi: 10.1523/JNEUROSCI.3377-16.2017

13. Bailey MR, Simpson EH, Balsam PD. Neural substrates underlying effort, time, and risk-based decision making in motivated behavior. Neurobiol Learn Mem. 2016; 133 (Sep): 233-256. doi: 10.1016/j.nlm.2016.07.015 
14. Hutchison MA, Gu X, Adrover MF et al. Genetic inhibition of neurotransmission reveals role of glutamatergic input to dopamine neurons in high-effort behavior. Molecular Psychiatry. 2018; 23 (5): 1213-1225. doi: 10.1038/ mp.2017.7

15. Barrot M, Sesack SR, Georges F et al. Braking dopamine systems: A new GABA master structure for mesolimbic and nigrostriatal functions. J Neurosci. 2012; 32 (41): 1409414101. doi: 10.1523/JNEUROSCI.3370-12.2012

16. Proulx CD, Aronson S, Milivojevic D et al. A neural pathway controlling motivation to exert effort. Proc. Natl. Acad. Sci. USA. 2018; 115 (22): 5792-5797. doi: 10.1073/ pnas. 1801837115

17. Felger IC, Li Z, Haroon E et al. Inflammation is associated with decreased functional connectivity within corticostriatal reward circuitry in depression. Mol. Psychiatry. 2016; 21 (10): 1358-1365. doi: 10.1038/mp.2015.168

18. Yohn SE, Arif Y, Haley A et al. Effort-related motivational effects of the pro-inflammatory cytokine interleukin-6: pharmacological and neurochemical characterization. Psychopharmacology. 2016; 233 (19-20): 3575-3586. doi: 10.1007/s00213-016-4392-9

19. Nunes EJ, Randall PA, Estrada A et al. Effort-related motivational effects of the pro-inflammatory cytokine interleukin 1-beta: studies with the concurrent fixed ratio 5/ chow feeding choice task. Psychopharmacology. 2014; 231 (4): 727-736. doi: 10.1007/s00213-013-3285-4

20. Salazar A, Gonzalez-Rivera BL, Redus L et al. Indoleamine 2,3-dioxygenase mediates anhedonia and anxietylike behaviors caused by peripheral ipopolysaccharide immune challenge. Hormon Behav. 2012; 62 (3): 202-209. doi: 10.1016/j.yhbeh.2012.03.010

21. Vichaya EG, Laumet G, Christian DL et al. Motivational changes that develop in a mouse model of inflammation-induced depression are independent of indoleamine 2,3 dioxygenase. Neuropsychopharmacology. 2019; 44 (2): 364-371. doi: 10.1038/s41386-018-0075-z

22. Rizvi SA, Pizzagalli DA, Sproule DA, Kennedy SH. Assessing anhedonia in depression: potentials and pitfalls. Neurosci Biobehav Rev. 2016; 65 (1): 21-35. doi: 10.1016/j. neubiorev.2016.03.004

23. Sescousse G, Caldú X, Segura B et al. Processing of primary and secondary rewards: a quantitative meta-analysis and review of human functional neuroimaging studies. Neurosci Biobehav Rev. 2013; 37 (4): 681-696. doi: 10.1016/j.neubiorev.2013.02.002

24. Nielsen CK, Arnt J, Sánchez C. Intracranial self-stimulation and sucrose intake differ as hedonic measures following chronic mild stress: interstrain and interindividual differences. Behav Brain Res. 2000; 107 (1): 21-33

25. Rizvi SJ, Quilty LC, Sproule BA et al. Development and validation of the Dimensional Anhedonia Rating Scale (DARS) in a community sample and individuals with major depression. Psychiatry Res. 2015; 229 (2): 109-119. doi: 10.1016/j.psychres.2015.07.062

26. Keedwell, PA, Andrew C, Williams SC et al. The neural correlates of anhedonia in major depressive disorder. Biol Psychiatry. 2005; 58 (11): 843-853. doi:10.1016/j. biopsych.2005.05.019

27. Grabenhorst F, Rolls ET. Value, pleasure and choice in the ventral prefrontal cortex. Trends Cogn Sci. 2011; 15 (2): 56-67. doi: 10.1016/j.tics.2010.12.004

28. Der-Avakian A, Markou A. The neurobiology of anhedonia and other reward-related deficits. Trends Neurosci. 2012; 35 (1): 68-77. doi: 10.1016/j.tins.2011.11.005

29. Berridge KC, Robinson TE. What is the role of dopamine in reward: hedonic impact, reward learning, or incentive salience? Brain Res Brain Res Rev. 1998; 28 (3): 309-369

30. Wassum KM, Ostlund SB, Maidment NT et al. Distinct opioid circuits determine the palatability and the desirability of rewarding events. Proc Natl Acad Sci USA. 2009; 106 (30): 12512-12517. doi: 10.1073/pnas.0905874106

31. Duman RS, Voleti B. Signaling pathways underlying the pathophysiology and treatment of depression: novel mechanisms for rapid acting agents. Trends Neurosci. 2012; 35 (1): 47-56. doi: 10.1016/j.tins.2011.11.004
14. Hutchison MA, Gu X, Adrover MF et al. Genetic inhibition of neurotransmission reveals role of glutamatergic input to dopamine neurons in high-effort behavior. Molecular Psychiatry. 2018; 23 (5): 1213-1225. doi: 10.1038/ mp.2017.7

15. Barrot M, Sesack SR, Georges F et al. Braking dopamine systems: A new GABA master structure for mesolimbic and nigrostriatal functions. J Neurosci. 2012; 32 (41): 1409414101. doi: 10.1523/JNEUROSCI.3370-12.2012

16. Proulx CD, Aronson S, Milivojevic D et al. A neural pathway controlling motivation to exert effort. Proc. Natl. Acad. Sci. USA. 2018; 115 (22): 5792-5797. . doi: 10.1073/ pnas. 1801837115

17. Felger IC, Li Z, Haroon E et al. Inflammation is associated with decreased functional connectivity within corticostriatal reward circuitry in depression. Mol. Psychiatry. 2016; 21 (10): 1358-1365. doi: 10.1038/mp.2015.168

18. Yohn SE, Arif Y, Haley A et al. Effort-related motivational effects of the pro-inflammatory cytokine interleukin-6: pharmacological and neurochemical characterization Psychopharmacology. 2016; 233 (19-20): 3575-3586. doi: 10.1007/s00213-016-4392-9

19. Nunes EJ, Randall PA, Estrada A et al. Effort-related motivational effects of the pro-inflammatory cytokine interleukin 1-beta: studies with the concurrent fixed ratio 5/ chow feeding choice task. Psychopharmacology. 2014; 231 (4): 727-736. doi: 10.1007/s00213-013-3285-4

20. Salazar A, Gonzalez-Rivera BL, Redus L et al. Indoleamine 2,3-dioxygenase mediates anhedonia and anxietylike behaviors caused by peripheral ipopolysaccharide immune challenge. Hormon Behav. 2012; 62 (3): 202-209. doi: 10.1016/j.yhbeh.2012.03.010

21. Vichaya EG, Laumet G, Christian DL et al. Motivational changes that develop in a mouse model of inflammation-induced depression are independent of indoleamine 2,3 dioxygenase. Neuropsychopharmacology. 2019; 44 (2): 364-371. doi: 10.1038/s41386-018-0075-z

22. Rizvi SA, Pizzagalli DA, Sproule DA, Kennedy SH. Assessing anhedonia in depression: potentials and pitfalls. Neurosci Biobehav Rev. 2016; 65 (1): 21-35. doi: 10.1016/j. neubiorev.2016.03.004

23. Sescousse G, Caldú X, Segura B et al. Processing of primary and secondary rewards: a quantitative meta-analysis and review of human functional neuroimaging studies. Neurosci Biobehav Rev. 2013; 37 (4): 681-696. doi: 10.1016/j.neubiorev.2013.02.002

24. Nielsen CK, Arnt I, Sánchez C. Intracranial self-stimulation and sucrose intake differ as hedonic measures following chronic mild stress: interstrain and interindividual differences. Behav Brain Res. 2000; 107 (1): 21-33

25. Rizvi SJ, Quilty LC, Sproule BA et al. Development and validation of the Dimensional Anhedonia Rating Scale (DARS) in a community sample and individuals with major depression. Psychiatry Res. 2015; 229 (2): 109-119. doi: 10.1016/j.psychres.2015.07.062

26. Keedwell, PA, Andrew C, Williams SC et al. The neural correlates of anhedonia in major depressive disorder. Biol Psychiatry. 2005; 58 (11): 843-853. doi:10.1016/j. biopsych.2005.05.019

27. Grabenhorst F, Rolls ET. Value, pleasure and choice in the ventral prefrontal cortex. Trends Cogn Sci. 2011; 15 (2): 56-67. doi: 10.1016/j.tics.2010.12.004

28. Der-Avakian A, Markou A. The neurobiology of anhedonia and other reward-related deficits. Trends Neurosci. 2012; 35 (1): 68-77. doi: 10.1016/j.tins.2011.11.005

29. Berridge KC, Robinson TE. What is the role of dopamine in reward: hedonic impact, reward learning, or incentive salience? Brain Res Brain Res Rev. 1998; 28 (3): 309-369

30. Wassum KM, Ostlund SB, Maidment NT et al. Distinct opioid circuits determine the palatability and the desirability of rewarding events. Proc Natl Acad Sci USA. 2009; 106 (30): 12512-12517. doi: 10.1073/pnas.0905874106

31. Duman RS, Voleti B. Signaling pathways underlying the pathophysiology and treatment of depression: novel mechanisms for rapid acting agents. Trends Neurosci. 2012; 35 (1): 47-56. doi: 10.1016/j.tins.2011.11.004 
32. Liechti ME, Markou A. Interactive effects of the mGlu5 receptor antagonist MPEP and the mGlu2/3 receptor antagonist LY341495 on nicotine self-administration and reward deficits associated with nicotine withdrawal in rats. Eur J Pharmacol. 2007; 554 (2-3): 164-174. doi:10.1016/j. eiphar.2006.10.011

33. El Yacoubi M, Dubois M, Gabriel C et al. Chronic agomelatine and fluoxetine induce antidepressant-like effects in $\mathrm{H} /$ Rouen mice, a genetic mouse model of depression. Pharmacol Biochem Behav. 2011; 100 (2): 284-288. doi: 10.1016/j.pbb.2011.08.001

34. Dremencov E, Newman ME, Kinor N et al. (2005) Hyperfunctionality of serotonin-2C receptor-mediated inhibition of accumbal dopamine release in an animal model of depression is reversed by antidepressant treatment. Neuropharmacology. 2005; 48 (1): 34-42. doi:10.1016/j. neuropharm.2004.09.013

35. Stein DJ. Anxiety symptoms in depression: clinical and conceptual consideration. Medicographia. 2013; 35 (4): 299-303

36. Insel T, Cuthbert B, Garvey M et al. Research domain criteria (RDoC): Toward a new classification framework for research on mental disorders. Am J Psychiatry. 2010; 167 (7): 748-751. doi: 10.1176/appi.ajp.2010.09091379

37. Davis M, Walker DL, Miles L et al. Phasic vs sustained fear in rats and humans: Role of the extended amygdala in fear vs anxiety. Neuropsychopharmacology. 2010; 35 (1): 105135. doi: 10.1038/npp.2009.109

38. Senn V, Wolff SB, Herry C et al. Long-range connectivity defines behavioral specificity of amygdala neurons. Neuron. 2014; 81 (2): 428-437. doi: 10.1016/j.neuron.2013.11.006

39. Pizzagalli DA. Frontocingulate dysfunction in depression: toward biomarkers of treatment response. Neuropsychopharmacol Rev. 2011; 36: 183-206

40. Kalin NH. Mechanisms underlying the early risk to develop anxiety and depression: A translational approach. Eur Neuropsychopharmacology. 2017; 27 (6): 543-553. doi: 10.1016/j.euroneuro.2017.03.004

41. Robinson OJ, Overstreet C, Allen PS et al. The role of serotonin in the neurocircuitry of negative affective bias: Serotonergic modulation of the dorsal medial prefrontal-amygdala 'aversive amplification' circuit. Neuroimage. 2013; 78 (1): 217-223. doi: 10.1016/j. neuroimage.2013.03.075

42. Абрамец И. И., Евдокимов Д. В., Зайка Т. О. ГАМКергические механизмы патогенеза и лечения депрессивного синдрома. Архив клин эксперим медицины. 2017; том 26, №1, с.46-54

43. Yates WR, Mitchell J, Rush AJ et al. Clinical features of depressed outpatients with and without co-occurring general medical conditions in STAR* D. Gen Hosp Psychiatry. 2004; 26 (6): 421-429. https://doi:10.1016/j. genhosppsych.2004.06.008

44. Matousek M, Cervena K, Zavesicka L et al. Subjective and objective evaluation of alertness and sleep quality in depressed patients. BMC Psychiatry. 2004; 4 (1): 14. doi: 10.1186/1471-244X-14-89

45. Peterson MJ, Benca RM. Sleep in mood disorders. Sleep Med Clin. 2008; 3 (2): 231-249

46. Mairesse J, Silletti V, Laloux C et al. Chronic agomelatine treatment corrects the abnormalities in the circadian rhythm of motor activity and sleep/wake cycle induced by prenatal restraint stress in adult rats. Int I Neuropsychopharmacol. 2013; 16 (2): 323-338. doi: 10.1017/ S1461145711001970

47. Le Dantec Y, Hache G, Guilloux JP et al. NREM sleep hypersomnia and reduced sleep/wake continuity in a neuroendocrine mouse model of anxiety/depression based on chronic corticosteroneadministration. Neuroscience.2014; 274:357-368. doi: 10.1016/j.neuroscience.2014.05.050

48. Scammell TE, Arrigoni E, Lipton J. Neural circuitry of wakefulness and sleep. Neuron. 2017; 93 (4): 747-765. doi: 10.1016/j.neuron.2017.01.014

49. Murphy M, Peterson MJ. Sleep disturbances in depression. Sleep Med Clin. 2015; 10 (1): 17-23. doi: 10.1016/j. jsmc.2014.11.009
32. Liechti ME, Markou A. Interactive effects of the mGlu5 receptor antagonist MPEP and the mGlu2/3 receptor antagonist LY341495 on nicotine self-administration and reward deficits associated with nicotine withdrawal in rats. Eur J Pharmacol. 2007; 554 (2-3): 164-174. doi:10.1016/j. eiphar.2006.10.011

33. El Yacoubi M, Dubois M, Gabriel C et al. Chronic agomelatine and fluoxetine induce antidepressant-like effects in $\mathrm{H} /$ Rouen mice, a genetic mouse model of depression. Pharmacol Biochem Behav. 2011; 100 (2): 284-288. doi: 10.1016/j.pbb.2011.08.001

34. Dremencov E, Newman ME, Kinor N et al. (2005) Hyperfunctionality of serotonin-2C receptor-mediated inhibition of accumbal dopamine release in an animal model of depression is reversed by antidepressant treatment. Neuropharmacology. 2005; 48 (1): 34-42. doi:10.1016/j. neuropharm.2004.09.013

35. Stein DJ. Anxiety symptoms in depression: clinical and conceptual consideration. Medicographia. 2013; 35 (4): 299-303

36. Insel T, Cuthbert B, Garvey $\mathrm{M}$ et al. Research domain criteria (RDoC): Toward a new classification framework for research on mental disorders. Am J Psychiatry. 2010; 167 (7): 748-751. doi: 10.1176/appi.ajp.2010.09091379

37. Davis M, Walker DL, Miles L et al. Phasic vs sustained fear in rats and humans: Role of the extended amygdala in fear vs anxiety. Neuropsychopharmacology. 2010; 35 (1): 105135. doi: 10.1038/npp.2009.109

38. Senn V, Wolff SB, Herry C et al. Long-range connectivity defines behavioral specificity of amygdala neurons. Neuron. 2014; 81 (2): 428-437. doi: 10.1016/j.neuron.2013.11.006

39. Pizzagalli DA. Frontocingulate dysfunction in depression: toward biomarkers of treatment response. Neuropsychopharmacol Rev. 2011; 36: 183-206

40. Kalin NH. Mechanisms underlying the early risk to develop anxiety and depression: A translational approach. Eur Neuropsychopharmacology. 2017; 27 (6): 543-553. doi: 10.1016/j.euroneuro.2017.03.004

41. Robinson OJ, Overstreet C, Allen PS et al. The role of serotonin in the neurocircuitry of negative affective bias: Serotonergic modulation of the dorsal medial prefrontal-amygdala 'aversive amplification' circuit. Neuroimage. 2013; 78 (1): 217-223. doi: 10.1016/j. neuroimage.2013.03.075

42. Abramets I.I., Evdokimov D.V., Zaika T.O. GAMKergicheskie mekhanizmy patogeneza i lecheniya depressivnogo sindroma. Arkhiv klin eksperim meditsiny. 2017; tom 26, №1, s.46-54 (in Russian).

43. Yates WR, Mitchell J, Rush AJ et al. Clinical features of depressed outpatients with and without co-occurring general medical conditions in STAR* D. Gen Hosp Psychiatry. 2004; 26 (6): 421-429. https://doi:10.1016/j. genhosppsych.2004.06.008

44. Matousek M, Cervena K, Zavesicka L et al. Subjective and objective evaluation of alertness and sleep quality in depressed patients. BMC Psychiatry. 2004; 4 (1): 14. doi: 10.1186/1471-244X-14-89

45. Peterson MJ, Benca RM. Sleep in mood disorders. Sleep Med Clin. 2008; 3 (2): 231-249

46. Mairesse J, Silletti V, Laloux C et al. Chronic agomelatine treatment corrects the abnormalities in the circadian rhythm of motor activity and sleep/wake cycle induced by prenatal restraint stress in adult rats. Int I Neuropsychopharmacol. 2013; 16 (2): 323-338. doi: 10.1017/ S1461145711001970

47. Le Dantec Y, Hache G, Guilloux JP et al. NREM sleep hypersomnia and reduced sleep/wake continuity in a neuroendocrine mouse model of anxiety/depression based on chronic corticosterone administration.Neuroscience. 2014; 274:357-368. doi: 10.1016/j.neuroscience.2014.05.050

48. Scammell TE, Arrigoni E, Lipton J. Neural circuitry of wakefulness and sleep. Neuron. 2017; 93 (4): 747-765. doi: 10.1016/j.neuron.2017.01.014

49. Murphy M, Peterson MI. Sleep disturbances in depression. Sleep Med Clin. 2015; 10 (1): 17-23. doi: 10.1016/j. jsmc.2014.11.009 
50. Aizawa H, Cui W, Tanaka K, Okamoto H. Hyperactivation of the habenula as a link between depression and sleep disturbance. Front Hum Neurosci 2013;7:1-6

51. Niciu MJ, Ionescu DF, Richards EM et al. Glutamate and its receptors in the pathophysiology and treatment of major depressive disorder, J Neural Transm. 2014; 121 (6): 907-924. doi: 10.1007/s00702-013-1130-x

52. Simmons WK, Burrows K, Avery JA et al. Depression-related increases and decreases in appetite: dissociable patterns of aberrant activity in reward and interoceptive neurocircuitry. Am J Psychiatry. 2016; 173 (4): 418-428. doi: 10.1176/appi.ajp.2015.15020162

53. Berthoud HR. Homeostatic and nonhomeostatic pathways involved in the control of food intake and energy balance. Obesity. 2006; 14 (Suppl 5): 197S-200S. https:// doi:10.1038/oby.2006.308

54. Basso AM, Kelley AE. Feeding induced by GABA (A) receptor stimulation within the nucleus accumbens shell: regional mapping and characterization of macronutrient and taste preference. Behav Neurosci. 1999;113 (2): 324 $-336$

55. Will MI, Franzblau EB, Kelley AE. Nucleus accumbens mu-opioids regulate intake of a high-fat diet via activation of a distributed brain network. J Neurosci. 2003;23 (7): 2882- 2888

56. Berridge KC. "Liking” and "wanting” food rewards: brain substrates and roles in eating disorders. Physiol Behav 2009; 97 (5): 537-550. doi: 10.1016/j.physbeh.2009.02.044

57. Zald DH. Orbitofrontal cortex contributions to food selection and decision making. Ann Behav Med 2009; 38 (suppl 1): S18-S24. doi: 10.1007/s12160-009-9117-4

58. Drevets WC: Orbitofrontal cortex function and structure in depression. Ann N Y Acad Sci. 2007; 1121 (Dec): 499527. https://doi:10.1196/annals.1401.029

59. Price JL, Drevets WC: Neurocircuitry of mood disorders. Neuropsychopharmacology. 2010; 35 (1): 192-216. doi: 10.1038/npp.2009.104

60. Simmons WK, Avery JA, Barcalow JC et al: Keeping the body in mind: insula functional organization and functional connectivity integrate interoceptive, exteroceptive, and emotional awareness. Hum Brain Mapp. 2013; 34 (11): 2944-2958. doi: 10.1002/hbm.22113. Epub 2012 Jun 13
50. Aizawa H, Cui W, Tanaka K, Okamoto H. Hyperactivation of the habenula as a link between depression and sleep disturbance. Front Hum Neurosci 2013;7:1-6

51. Niciu MJ, Ionescu DF, Richards EM et al. Glutamate and its receptors in the pathophysiology and treatment of major depressive disorder, J Neural Transm. 2014; 121 (6): 907-924. doi: 10.1007/s00702-013-1130-x

52. Simmons WK, Burrows K, Avery JA et al. Depression-related increases and decreases in appetite: dissociable patterns of aberrant activity in reward and interoceptive neurocircuitry. Am J Psychiatry. 2016; 173 (4): 418-428. doi: 10.1176/appi.ajp.2015.15020162

53. Berthoud HR. Homeostatic and nonhomeostatic pathways involved in the control of food intake and energy balance. Obesity. 2006; 14 (Suppl 5): 197S-200S. https:// doi:10.1038/oby.2006.308

54. Basso AM, Kelley AE. Feeding induced by GABA (A) receptor stimulation within the nucleus accumbens shell: regional mapping and characterization of macronutrient and taste preference. Behav Neurosci. 1999;113 (2): 324 $-336$

55. Will MJ, Franzblau EB, Kelley AE. Nucleus accumbens mu-opioids regulate intake of a high-fat diet via activation of a distributed brain network. J Neurosci. 2003;23 (7): 2882- 2888

56. Berridge KC. "Liking” and "wanting” food rewards: brain substrates and roles in eating disorders. Physiol Behav 2009; 97 (5): 537-550. doi: 10.1016/j.physbeh.2009.02.044

57. Zald DH. Orbitofrontal cortex contributions to food selection and decision making. Ann Behav Med 2009; 38 (suppl 1): S18-S24. doi: 10.1007/s12160-009-9117-4

58. Drevets WC: Orbitofrontal cortex function and structure in depression. Ann N Y Acad Sci. 2007; 1121 (Dec): 499527. https://doi:10.1196/annals.1401.029

59. Price JL, Drevets WC: Neurocircuitry of mood disorders. Neuropsychopharmacology. 2010; 35 (1): 192-216. doi: 10.1038/npp.2009.104

60. Simmons WK, Avery JA, Barcalow JC et al: Keeping the body in mind: insula functional organization and functional connectivity integrate interoceptive, exteroceptive, and emotional awareness. Hum Brain Mapp. 2013; 34 (11): 2944-2958. doi: 10.1002/hbm.22113. Epub 2012 Jun 13 